\title{
Assessing Single Particle Soot Photometer and Integrating Sphere/Integrating Sandwich Spectrophotometer measurement techniques for quantifying black carbon concentration in snow
}

\author{
J. P. Schwarz ${ }^{1,2}$, S. J. Doherty ${ }^{3}$, F. Li ${ }^{4}$, S. T. Ruggiero ${ }^{4}$, C. E. Tanner ${ }^{4}$, A. E. Perring ${ }^{1,2}$, R. S. Gao ${ }^{1}$, and D. W. Fahey ${ }^{1,2}$ \\ ${ }^{1}$ Chemical Sciences Division, Earth System Research Laboratory, National Oceanic and Atmospheric Administration, \\ Boulder, Colorado, USA \\ ${ }^{2}$ Cooperative Institute for Research in Environmental Sciences, University of Colorado, Boulder, Colorado, USA \\ ${ }^{3}$ JISAO, University of Washington, Seattle, Washington, USA \\ ${ }^{4}$ Department of Physics, University of Notre Dame, Notre Dame, Indiana, USA
}

Correspondence to: J. P. Schwarz (joshua.p.schwarz@ noaa.gov)

Received: 20 March 2012 - Published in Atmos. Meas. Tech. Discuss.: 29 May 2012

Revised: 28 September 2012 - Accepted: 1 October 2012 - Published: 1 November 2012

\begin{abstract}
We evaluate the performance of the Single Particle Soot Photometer (SP2) and the Integrating Sphere/Integrating Sandwich Spectrophotometer (ISSW) in quantifying the concentration of refractory black carbon (BC) in snow samples. We find that the SP2 can be used to measure BC mass concentration in snow with substantially larger uncertainty $(60 \%)$ than for atmospheric sampling $(<30 \%)$. Achieving this level of accuracy requires careful assessment of nebulizer performance and SP2 calibration with consideration of the fact that $\mathrm{BC}$ in snow can exist in larger sizes than typically observed in the atmosphere. Once these issues are addressed, the SP2 is able to measure the size distribution and mass concentration of $\mathrm{BC}$ in the snow. Laboratory comparison of the SP2 and the ISSW revealed significant biases in the estimate of BC concentration from the ISSW when test samples contained dust or nonabsorbing particulates. These results suggest that current estimates of BC mass concentration in snow or ice formed from fallen snow using either the SP2 or the ISSW may be associated with significant underestimates of uncertainty.
\end{abstract}

\section{Introduction}

The effect of absorbing impurities on snow albedo is a critical parameter influencing the planetary albedo and, hence, the radiative balance of the Earth system (e.g., Flanner et al.,
2007). A priori modeling of the impact of snow albedo on the radiation budget is a challenging task because snow albedo depends on many complex factors including snow structure ("grain size," which depends on the temperature history of the snow), amount and composition of contaminants, snow depth, and characteristics of the underlying surface (including the presence of tall grasses or trees). Within this complicated framework, scientists have been working towards identifying the incremental contribution of a particular contaminant - combustion-generated refractory black carbon (BC) on the snow's absorption of light.

The Single Particle Soot Photometer (SP2, Schwarz et al., 2008, Droplet Measurement Technology, Inc., Boulder, CO, USA) is an aerosol instrument with the ability to quantify the mass concentration and size distribution of $\mathrm{BC}$ in atmospheric aerosol without significant sensitivity to other materials, and thus is a natural choice for application to measurements of BC in snow. McConnell et al. (2007), Bisiaux et al. (2012a, b) and Kaspari et al. (2011) have used it to measure $\mathrm{BC}$ in cores formed from fallen snow, and Ohata et al. (2011) have applied it to BC in rainwater. However, applying the SP2 to determining BC size distribution and concentration in water (or snow/ice melt) requires a careful assessment of additional uncertainties introduced by the need to aerosolize the liquid, and by the potential presence of much larger BC particles than are typically observed in the atmosphere. The assessment provided here is for snow 
samples, but we expect it to translate well to measurements of BC in ice formed from fallen snow.

The Integrating Sphere/Integrating Sandwich Spectrophotometer (ISSW, Grenfell et al., 2011) is a new instrument based on combining and modifying elements of previous instrument designs (including the Integrating Sandwich, Clarke et al., 1987). The ISSW measures the wavelengthresolved absorption of particulate material collected on filters from melted snow samples. The BC concentration of the filtrate is determined by quantifying the fraction of absorption associated with the wavelength $(\lambda)$ dependence believed to be characteristic of $\mathrm{BC}$ aerosol, $\lambda^{-1}$. The remainder of the absorption is attributed to other (non-BC) particulate constituents. The ISSW's estimates of BC concentration rely on conversion of measured absorption to BC mass using a set of calibration standards prepared in the laboratory.

The ISSW has been used to chart BC loadings in a panArctic snow study, which attributed at least half of solar absorption by particulate snow impurities to BC (Doherty et al., 2010). The ISSW neither has been directly compared against independent assessments of BC concentration in snow, nor has it previously been tested with laboratory standards containing non-BC materials in addition to $\mathrm{BC}$.

Here we apply the SP2 to quantifying BC concentration and size distribution in snow (Sect. 2.1), briefly describe the ISSW (Sect. 2.2), present preparation of laboratory samples (Sect. 2.3), and then compare SP2 and the ISSW measurements of laboratory standards including BC, dust, and scattering particulate in Sect. 3. Section 4 summarizes our conclusions and their implications.

\section{Experimental}

\subsection{SP2 technique for $\mathrm{BC}$ in snow}

The SP2 uses an intense intra-cavity laser (1064 nm) to heat the refractory BC component of individual aerosol particles to vaporization. At vaporization the peak visible thermal radiation emitted by the $\mathrm{BC}$ is measured to constrain the colortemperature of the hot material (and thus BC composition) and to provide a measure of its mass. This detection method is not affected by the mixing state or morphology of the particles for most of the BC mass observed in the ambient atmosphere (Cross et al., 2010; Moteki and Kondo, 2010). Mass loadings in air are quantified by integrating the individual BC masses associated with individual particles detected within a given amount of air. We convert the measured mass of BC in a particle to a volume-equivalent diameter (VED) by assuming a void-free density of $1.8 \mathrm{~g} \mathrm{~cm}^{-3}$.

$\mathrm{SP} 2$ measurements of $\mathrm{BC}$ in snow require consideration of two issues not directly associated with the SP2's use for quantifying BC in air. First, the efficiency with which the particles in liquid are mixed with air and then transported to the SP2 laser must be known; in general, this is a function of particle size. Second, the SP2 range of detection must be extended to larger sizes than typically encountered in the atmosphere, because, as we find here, the $\mathrm{BC}$ size distribution in snow samples can extend to substantially larger sizes than those typically found in the atmosphere. This requires calibration of the mass-vs-thermal emission relationship to large mass, as well as statistical analysis of the impact of large, rare $\mathrm{BC}$ particles on the mass integral. Section 2.1.1 presents the approach used to calibrate the SP2 for large BC particles. Section 2.1.2 discusses aerosolization of particulates in liquids such as melted snow and Sect. 2.1.3 presents the size distribution of BC observed in snow melt and its impact on SP2 uncertainties.

\subsubsection{Calibration of the SP2}

The SP2 was calibrated with fullerene soot (Alfa Aesar, Inc., Ward Hill, MA, USA, Lot\# F12S011) over a range of 0.5$40 \mathrm{fg}$ (corresponding to $\sim 80-350 \mathrm{~nm}$ volume-equivalent diameter (VED) assuming a density of $1.8 \mathrm{~g} \mathrm{~cm}^{-3}$ ) selected with a DMA. Fullerene soot is the recommended material for calibrating the SP2 for ambient measurements of BC (Baumgardner et al., 2012). This calibration range typically covers $>75 \%$ of ambient accumulation mode mass. The calibration of mobility diameter to $\mathrm{BC}$ mass for this material over this range was provided by averaging the results of Moteki and Kondo (2010) and Gysel et al. (2011). Over this range, the calibration of SP2-determined peak height to mass for the BC particles was very close to purely linear, and both published mass-to-mobility relationships are in good agreement; hence we did not extend our basic calibration to a wider mass range.

For larger BC particles, the empirical power-law dependences in Moteki and Kondo (2010) were used. The Moteki and Kondo dependences (shown graphically in their Fig. 9) relate SP2 detection signal to $\mathrm{BC}$ mass raised to a power that is anti-correlated to the material's density, and were measured up to near $600 \mathrm{~nm}$ VED. A power of 0.9 was chosen as intermediate between that of the ambient $\mathrm{BC}$ observed in Tokyo during that study (0.95) and that of the densest $\mathrm{BC}$ identified by Moteki and Kondo as formed of agglomerations of primary particles $(0.85)$. Hence, a function of the form $P_{\mathrm{h}}=A m^{0.9}$ was used to fit the fullerene data peak-height to mass calibration discussed above, where $P_{\mathrm{h}}$ is the modal peak height measured by the SP2 for a fullerene particle of known mass, $m$, and $A$ is the fitted variable. The resulting optimal value of $A$ was used to determine the masses associated with the large $\mathrm{BC}$ particles observed here. Note that, normally, BC particles larger than the traditional detection limit of the SP2 are detected, but discarded in post-acquisition analysis due to their saturation of the SP2 detectors; in atmospheric measurements they are not large contributors to SP2 uncertainty. To enable detection of large BC without saturating SP2 detectors, we operated the instrument with both staggered gain between the two color-band incandescent 
detectors, and with both detectors run at matching gain that was varied over $1-25$ count/fg sensitivity. In this way we were able both to confirm $\mathrm{BC}$ composition via the color-ratio measured for large $\mathrm{BC}$ and to cover the entire mass range of interest.

A sensitivity study using the more extreme power values when fitting for $A$ showed a range of $20 \%$ in the inferred $\mathrm{BC}$ mass for the larger size distributions observed here in snow, which extend to $2000 \mathrm{~nm}$ VED (Sect. 2.1.3). Because this extrapolation extends so far in mass space, we double the range of the inferred mass to estimate the uncertainty associated with the contribution of large BC masses to total BC mass. Hence the total uncertainty we associate with the calibration of the SP2 is $50 \%$, driven primarily by a $30 \%$ uncertainty in the range of SP2 response to different BC materials (a very conservative estimate based on the results of Moteki and Kondo, 2010 and Gysel et al., 2011) added in quadrature with $40 \%$ uncertainty due to the extrapolation of SP2 calibration to large sizes. Direct calibration using an Aerosol Particle Mass Analyzer (Kanomax USA Inc., Andover, NJ) or Couette Particle Mass Analyzer (Olfert and Collings, 2005), which were not available for this study, could reduce this uncertainty. An approach to doing so would be to directly select denuded snow-BC by mass, and test the performance of the extrapolation. Alternatively, a technique such as 3-Dtomography (e.g., Adachi et al., 2010) of snow-bound BC may be able to contribute to our understanding of both the morphology and mass-contribution of large $\mathrm{BC}$. Given that the number concentration of large $\mathrm{BC}$ in the snow is very low, these are both daunting tasks. We also note that not all snow or ice formed from fallen snow necessarily contains $\mathrm{BC}$ larger than observed in the ambient atmosphere; the spatial/temporal variability of BC size in snow is presently unknown.

Laser intensity was measured with polystyrene latex spheres (PSLs) as described in Schwarz et al. (2010a). The SP2 was operated with laser intensity $\sim 700 \mathrm{nW} /(220-\mathrm{nm}$ PSL), slightly higher than the maximum intensity of that study. This intensity was sufficient to insure proper detection of $\mathrm{BC}$ over the range studied here including the large particles. Note that, with sufficient laser intensity, the SP2 calibration to BC mass is independent of laser intensity.

\subsubsection{Aerosolization of particulates in snow melt}

The SP2 can only sample aerosol, which we generated from liquid samples with a Collison-type nebulizer ("CNEB") that was built in-house and is similar to a commercial TSI Collison nebulizer \#3076 (TSI Inc., Shoreview, MN). The nebulizer uses a stream of pressurized air expanding through a critical orifice to shear liquid into small droplets that are then dried out, releasing any particulate contained in the droplets to the air. The liquid samples were pumped into the nebulizer with a peristaltic pump at well-controlled rates of $0.004 \mathrm{~cm}^{3} \mathrm{~s}^{-1}$. The instability in the rate of flow in the peristaltic pump is a negligible contributor to the total uncertainty. The length of the peristaltic pump line was varied to test for losses of $\mathrm{BC}$ from the liquid phase. No dependence on line length was observed, yet there were clear signs that, when very concentrated mixtures were passed through the line (for example to provide $\mathrm{BC}$ for size selection with a differential mobility analyzer), residues of $\mathrm{BC}$ on the line were released into the next solutions sampled. This suggests whatever loss/resuspension of BC to the pump line occurs, its most significant impact is likely in adding additional, contaminant $\mathrm{BC}$ to relatively clean samples, rather than decreasing the $\mathrm{BC}$ concentration associated with dirtier samples. To avoid these issues and minimize the $\mathrm{BC}$ contamination, we used new, clean peristaltic pump lines for sampling snow and laboratory concentration samples after more concentrated solutions, and observed contamination in the range equivalent to $0.05-0.5 \mathrm{ng} \mathrm{g}^{-1} \mathrm{BC}$ concentration. The lower end of this range was limited by stray BC particles in the SP2 laser head, rather than by $\mathrm{BC}$ contained in the air stream from the nebulizer. Clearly, depending on the concentration in an unknown sample, care must be taken to establish that the background is suitably low.

Our work with the nebulizer revealed that different size particles were aerosolized with different efficiencies, with larger particles having a reduced likelihood to be passed to the SP2. We assume that these differences result from the internal geometry of the nebulizer, which requires sharp turns of the airflow that may act to strip the air of larger particles (see, for example Hinds, 1999). Based on separate tests of transport efficiency of different size particles in the SP2 (Schwarz et al., 2006), we believe that these losses occur predominately in the nebulizer. To address this issue, we adopt an empirical approach to the problem, by simply directly measuring the efficiency with which particles in liquid were nebulized and transported to the SP2, as follows.

We used polystyrene latex sphere (PSL) concentration standards (Polysciences Inc., Warrington, PA, USA) in sizes of $220,356,505,771,1025$, and $1537 \mathrm{~nm}$ diameter to test both the Collison nebulizer and an ultrasonic nebulizer, the U5000AT (U5000AT, CETAC Technologies, Omaha, NE, USA), which was used in previous SP2 determinations of BC in ice formed from fallen snow and rainwater (McConnell et al., 2007; Bisiaux et al., 2012a, b; Ohata et al., 2011; Kaspari et al., 2011). PSLs have a density of $1.05 \mathrm{~g} \mathrm{~cm}^{-3}$. PSLnumber concentration standards in water were generated using the solid fraction weight provided by the manufacturer and checked against laser transmission spectroscopy (LTS, Li et al., 2010), which confirmed the concentrations to $7 \%$, excepting the $220 \mathrm{~nm}$ standard, which was used without confirmation from the LTS. The following equation was used to calculate the PSL number concentration (from technical note \#206 at http://www.bangslabs.com/literature/technotes): 
$C=1.91 \times 10^{12} P_{\mathrm{w}} /\left[\left(P_{\mathrm{w}} \cdot(-0.05)+105\right) \cdot D^{3}\right]$

where $C$ is the number of PSLs of diameter $D$ in micrometers and density $1.05 \mathrm{~g} \mathrm{~cm}^{-3}$ in $1 \mathrm{~cm}^{3}$ of solution (made with water), when $P_{\mathrm{w}}$ is the weight percentage of the PSL in the solution (specified by the manufacturer). The standards were diluted to $\sim 5 \times 10^{8}$ particles $\mathrm{cm}^{-3}$ for use with the CNEB and SP2.

The absolute nebulization and (transmission) efficiency of each given PSL size to the SP2 laser, where detection occurs, was determined by measuring, with the SP2, the airborne concentration of the PSL particles. As the PSL concentration in the liquid standard was known, this is essentially a measure of the liquid volume containing the number of particles that the nebulizer aerosolized into a given volume of air. Note that, as different size particles have different efficiencies, this is not simply a measure of the actual amount of liquid being mixed into the air. The absolute efficiency, $E$, at a given size was calculated with

$E=C_{\mathrm{a}} / C_{1}$

where $C_{\mathrm{a}}$ was the airborne number concentration of the PSLs $\left(\# / \mathrm{cm}^{-3}\right)$, and $C_{1}$ was the liquid number concentration $(\# / \mathrm{g})$. Depending on choice of concentration units in liquid and in air, the units of $E$ may change. We used number per gram for the liquid because water (with density $1 \mathrm{~g} \mathrm{~cm}^{-3}$ ) was the primary component. For the particular setup of flows/liquid pumping rate we used, this efficiency was of the order of $60 \mathrm{ng} \mathrm{cm}^{-3}$ for $505 \mathrm{~nm}$ PSLs - i.e., only the $505 \mathrm{~nm}$ PSLs contained in about 60 billionths of a gram of liquid were effectively aerosolized into each cubic centimeter of air sampled by the SP2. Knowing the particular pump/flow parameters used (in this case liquid pump rate $Q_{\mathrm{p}}$ of $4 \mathrm{mg} \mathrm{s}^{-} 1$, and air flow, $Q_{\mathrm{a}}$, of $10 \mathrm{~cm}^{3} \mathrm{~s}^{-1}$ ), we can also calculate the fraction of pumped liquid effectively aerosolized for the given size, $F$ :

$F=E \times Q_{\mathrm{a}} / Q_{\mathrm{p}}$.

In this case about $0.02 \%$ of the liquid pumped was effectively aerosolized for the particular size PSL tested. We stress that these results are not universal, and must be measured for each nebulizer used. Also, in terms of determining the effect of the size sensitive aerosolization of the nebulizer on $\mathrm{BC}$ concentrations, the absolute value of the efficiency at a given size is not as important (so long as it was known) as the relative efficiency between different sized particles.

For these measurements, only particles within the appropriate size range of the PSLs were counted in the aerosol state (i.e., agglomerations or PSL fragments were not included). Aerosol particles outside the appropriate size range were very scarce, but the $505 \mathrm{~nm}$ PSL standard was particularly clean. Hence we used the $505 \mathrm{~nm}$ size to provide the relative reference in Fig. 1, which shows the nebulization efficiency of other PSL sizes with respect to that for $505 \mathrm{~nm}$.

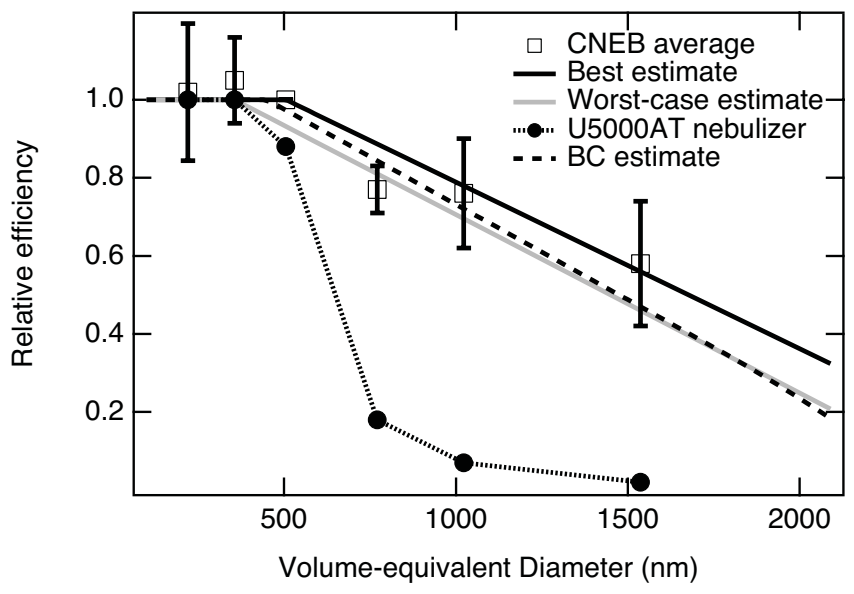

Fig. 1. Relative transmission efficiencies of PSLs in liquid to the SP2 after aerosolization with a Collison-type nebulizer. The results are scaled to the transmission of $505 \mathrm{~nm}$ PSLs, for which the absolute efficiency of aerosolization was approximately $1 \mu \mathrm{gg}^{-1}$. The measured relative efficiency for the U5000AT ultrasonic nebulizer is also shown, as is an estimated curve for $\mathrm{BC}$ nebulized with the Collison-type nebulizer.

The nebulization efficiency was parameterized as a function of PSL diameter for eventual correction of BC mass mixing ratios measured with the same nebulizer and operating parameters. For sizes below $500 \mathrm{~nm}$, it was modeled as unity. We then fit a line to the relative efficiencies for sizes larger than $500 \mathrm{~nm}$, fixing the intercept at $500 \mathrm{~nm}$ to unity. This produced the "best-estimate" efficiency curve in Fig. 1. To test sensitivity to the correction to this parameterization, we also produced a line intercepting 1 at $350 \mathrm{~nm}$, and roughly tracing the lowest relative efficiencies at larger sizes (dashed line in Fig. 1). This is the "worst-case" efficiency curve.

The U5000AT was found to aerosolize PSLs larger than $\sim 600 \mathrm{~nm}$ with very poor efficiency (i.e., $\lesssim 10 \%$ ) with respect to smaller particles, as shown in Fig. 1. The U5000AT also produced $\mathrm{BC}$ size distributions that had essentially no mass contribution from BC particles larger than $\sim 500 \mathrm{~nm}$ VED. These measurements were not exhaustively tested, but appeared robust under limited exploration of the nebulizer air flow rate, liquid pump rate, and chiller temperature. Hence we do not associate uncertainty whiskers with the U5000AT result. However, another laboratory has verified that, over the smaller size range of $150-450 \mathrm{~nm}$, PSLs had flat transmission efficiency in this nebulizer, consistent with our result (McConnell, AMTD Referee Comment). As we show later, there can be significant BC mass contributions in sizes larger than this; hence the U5000AT was not used here, and we recommend in-depth examination of its behavior over the entire relevant size range to those intending to apply it to aerosolizing $\mathrm{BC}$ from a liquid sample.

Application of the nebulization efficiency curves, which were based on PSL measurements, to correct observed BC 
mass distributions was conducted by assuming that the nebulization efficiency was a function of particle stopping distance, $S$, itself proportional to particle diameter $(D)$ squared, and linearly proportional to the particle density, $\rho$ :

$S=\frac{\rho D^{2} C_{\mathrm{c}}}{18 \eta} U$

where $C_{\mathrm{c}}$ is the slip correction factor, $U$ is the particle speed relative to still air, and $\eta$ is the air dynamic viscosity (Hinds, 1999). The PSL density and sizes were well known. For BC, we adopted a value for the effective density of $0.8 \mathrm{~g} \mathrm{~cm}^{-3}$, which is the average density measured between 400-900 nm mobility diameter for six BC materials in Moteki and Kondo (2010); these materials did not include the glassy carbon spheres from that study, which clearly do not relate to $\mathrm{BC}$ structure in the ambient, and have much higher density, but did include presumably fresh $\mathrm{BC}$ measured in Tokyo with an effective density of only $0.3 \mathrm{~g} \mathrm{~cm}^{-3}$. Such a low effective density is likely not appropriate for processed BC such as would be found in snow, and would therefore result in very short calculated stopping distances and thus underestimate the losses of larger BC. Therefore, we believe the $0.8 \mathrm{~g} \mathrm{~cm}^{-3}$ density estimate is reasonably conservative, although it is clear that uncertainty in the actual effective density of the $\mathrm{BC}$ translates into uncertainty in the nebulizer losses.

The SP2 determination of BC mass was used in conjunction with the assumed effective density to calculate the stopping distance of the particles. Note that the choice of $U$ is arbitrary in this approach, as we assume that it is the same for both BC and PSLs. Figure 1 includes the efficiency curve for $\mathrm{BC}$ with an assumed density of $0.8 \mathrm{~g} \mathrm{~cm}^{-3}$, based on the best case PSL curve. Here, for consistency, the diameter of the BC particle corresponds, still, to the $1.8 \mathrm{~g} \mathrm{~cm}^{-3}$ used in the generation of the size distributions presented in the next section. Our results (Sect. 3) suggest that the presence of non-BC materials internally mixed on $\mathrm{BC}$ in nebulized, melted snow will not significantly affect the net particle mass or density; note that this may not always be the case. Five size distributions of BC from first-melt snow samples were scaled with both the best-estimate and worst-case efficiency curves (discussed in Sect. 2.1.3, the best-estimate average of which is shown in Fig. 2). On average, the best-estimate nebulization efficiency parameterization led to a $25 \%$ shift upwards in total $\mathrm{BC}$ mass, and the worst case produced an average correction of nearly $50 \%$. Changing only the assumed density from 0.8 to $0.9 \mathrm{~g} \mathrm{~cm}^{-3}$ for the $\mathrm{BC}$ material had essentially no impact on our best-estimate of the correction due to imperfect nebulization efficiency. Hence, we suggest that an uncertainty estimate of $30 \%$ associated with the size-dependent nebulization efficiency determination is reasonable for this system and snow samples. This uncertainty $(30 \%)$ added in quadrature to the $50 \%$ uncertainty due to the $\mathrm{BC}$ calibration results in a total SP2 uncertainty estimate of $60 \%$. Note that the uncertainty associated with quantifying $\mathrm{BC}$ mass concentration

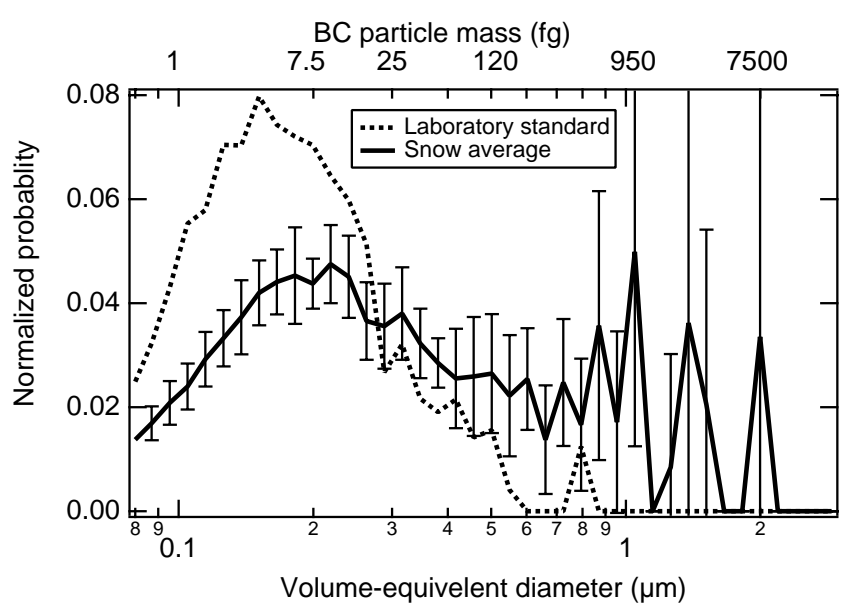

Fig. 2. Mass distributions from five first-melt snow samples from Colorado measured with the SP2 (heavy line). The whiskers indicate the standard deviation about the mean. Also shown is the mass distribution of the laboratory BC standard, which is similar to that typically observed in the ambient atmosphere (dashed). The vertical axis is $d M / d \log (D)$ with all distributions normalized to an area of 1. These mass distributions were scaled with the best-estimate nebulizer efficiency curve to represent the actual size distribution of the $\mathrm{BC}$ in the liquid.

in liquid in cases of smaller BC size distribution than those seen here would likely be lower.

\subsubsection{BC size distributions in snow}

The impact of the nebulization efficiency curves on the BC mass observed by the SP2 depends on the underlying size distribution of the particulate material in the liquid, which we assume here is not shifted from that of the unmelted snow during melting in the laboratory. Note that the size distribution itself, in addition to the $\mathrm{BC}$ concentration in snow, may be of scientific interest, for example because it could affect $\mathrm{BC}$ mass absorption efficiency, and hence snow albedo. We find that freeze/thaw cycles affect BC size distributions in water; hence it is also possible that the size distribution can give information about the thermal history of the snow, or about the mechanisms by which snow forms.

As a first estimate of the likely range of $\mathrm{BC}$ size to be found in snow, we examined fresh local snow and field samples from the Arctic. The local snow was collected within $60 \mathrm{~km}$ of Denver, CO, in both semi-rural and rural areas. The local snow samples were collected in pre-chilled glass containers, pre-chilled glass containers, stored in deep freeze, and then thawed in a microwave oven for immediate sampling with the SP2. Figure 2 shows the average mass distribution calculated from five local first-melt snow samples. The size distributions directly observed by the SP2 (not shown) were individually scaled with the best-estimate CNEB efficiency curve as discussed in Sect. 2.1.1. 
The Arctic field samples were collected, then kept frozen until they were melted rapidly in the laboratory with a microwave oven, usually within a few days of being gathered in the field. They were then decanted into high-density polypropylene (HDPE) bottles and immediately deep-frozen for storage before transport. During transport, these samples were partially thawed for a period of approximately 1 day, then refrozen for storage. Due to this somewhat extended processing, we do not present quantitative results from the Arctic samples.

For sampling in the SP2, the field samples were thawed in a sonicator where they were agitated for $20 \mathrm{~min}$, and then immediately sampled with the SP2 without agitation. After sampling, they were acidified to $0.5 \mathrm{M}$ nitric acid, as per Kaspari et al. (2011), then sonicated for another $20 \mathrm{~min}$ before resampling with the SP2. There was reduction in the mass fraction of super-micron $\mathrm{BC}$ particles after the acidification step, likely due to the acid helping break apart coagulated $\mathrm{BC}$ fragments. This did not come close to reducing the $\mathrm{BC}$ size to that in the atmosphere, but did essentially eliminate $\mathrm{BC}$ larger than $1500 \mathrm{~nm}$. Thus, if the $\mathrm{BC}$ size distribution in snow is of interest, acidification should not be carried out. Note that the SP2 did not show significant dependency in BC concentration on whether the sample was agitated or not during sampling.

Many of the snow samples had significant BC mass contributions at larger sizes than in typical ambient air (where typically $>90 \%$ of the BC mass is below $600 \mathrm{~nm}$ VED). The peak diameters of the mass distribution of the sample average shown in Fig. 2 were similar to that for typical atmospheric $\mathrm{BC}$, but some of the samples contributed more strongly to the larger-BC size fraction. Hence it appears likely that there is significant variability in the size distribution of BC in snow. We use the local first-melt snow average distribution to calculate a reasonable uncertainty analysis of the SP2 technique for BC in snow (Sect. 2.1.2).

Testing with laboratory standards as well as with fresh local snow showed that individual freeze/thaw cycles cause the agglomeration of a small fraction of $\mathrm{BC}$ mass into larger sizes, without dramatically shifting the underlying $\mathrm{BC}$ size distribution. It follows that the most accurate measurement of the BC size distribution will be from the first melt of the particular snow sample in question. Laboratory standards were tested up to high concentrations of $\mathrm{BC}$ equivalent to the largest loadings reported in the literature (Table 1, discussed in Sect. 2.3), and the BC size distribution was independent of $\mathrm{BC}$ concentration. This indicates that the large BC particles observed in snowmelt are not merely artifacts of the nebulization process. Note that, throughout these tests, the airborne $\mathrm{BC}$ concentration was low enough that particle coincidence issues in the SP2 were negligible.

The fact that the $\mathrm{BC}$ mass distributions peak well below the range where the nebulizer efficiency has clearly declined suggests that mass contributions of large BC agglomerations are not likely to cause significant underestimation in our treatment; i.e., we are unlikely to have missed detection of an entire mode of larger BC. This assumption, of course, may not hold for all samples, in which case this technique would only provide a lower limit on BC concentration. Clearly, the uncertainty associated with the SP2 determination of $\mathrm{BC}$ concentration in water will depend on the characteristics of the individual nebulizer used, as well as the underlying size distribution of BC-containing particles, and the technique used to calibrate the nebulization efficiency. For example, if a gravimetric standard is used to calibrate the nebulizer, then errors may occur if the size distribution of the experimental sample is not the same of that of the standard, depending on the nebulization efficiency size dependence of the nebulizer. Note that our measurements indicate that BC tended not to be internally mixed with much non-BC material in our aerosolized melted snow samples (Sect. 3).

In typical ambient air samples, only a small correction is required to scale the observed mass to the mass of $\mathrm{BC}$ within the entire accumulation mode, because the detection range of the SP2 is typically only slightly narrower than that of BC in the ambient (Schwarz et al., 2010b), and the assumption that negligible BC mass exists in sizes below the SP2 detection threshold is generally valid. This is not true of very fresh emissions, which tend to smaller sizes than reliably detectable by the SP2. Due to the increased uncertainties associated with SP2 measurements of BC larger than typically seen in the ambient air, any method one can use to break particles into smaller sizes will improve the concentration measurement (so long as they are not broken down to sizes below the practical SP2 detection range). We assume, based on the clear decrease in $\mathrm{BC}$ mass concentration towards the lower size limit of the SP2, that there is negligible BC mass below the SP2 detection range in all the snow samples. As stated above, we found that acidification of the field samples following Kaspari et al. (2011), nominally to release $\mathrm{BC}$ from container walls), followed by sonication for $20 \mathrm{~min}$ broke down some of the large BC agglomerations (Fig. 2). However, measurements with the SP2 indicated that, in highdensity polyethylene bottles, $\mathrm{BC}$ losses in samples at room temperature for even one day were significant (highly variable, but of the order of $50 \%$ ), and acidification failed to restore most $\mathrm{BC}$ lost to walls. $\mathrm{BC}$ losses in glass containers at room temperature were much more limited.

A large number, of the order of 10000 , of BC-containing particles need be sampled to reduce the statistical uncertainty associated with the incremental detection of individual large particles; these are rare but may contain a significant fraction of the total BC mass. In snow samples in which BC is very dilute, yet which include large particles, this could require long integration times. A straightforward way to estimate the statistical uncertainty associated with these types of measurements is to compare the concentrations measured twice over equal integration times. For the ambient samples tested here, we found that subsequent 5 min integrations (each using 2 gr liquid) were typically sufficient to 
Table 1. Laboratory sample information. Labels beginning with "B" refer to pure BC in water; those beginning with " $D$ " refer to samples that include dust with or without BC. Samples with PSLs are not included here (as discussed in the text). The ISSW results were calculated for $\alpha=4.4$.

\begin{tabular}{|c|c|c|c|c|c|c|c|}
\hline $\begin{array}{l}\text { Sample } \\
\text { label }\end{array}$ & $\begin{array}{l}\text { Gravimetric } \\
\mathrm{BC}\left(\mathrm{ng} \mathrm{g}^{-1}\right)\end{array}$ & $\begin{array}{r}\text { Gravimetric } \\
\text { dust } \\
\left(\mu g^{-1}\right)\end{array}$ & $\begin{array}{r}\mathrm{SP} 2 \\
\mathrm{BC}\left(\operatorname{ng~g~}^{-1}\right)\end{array}$ & $\begin{array}{r}\text { ISSW } \\
\text { BC }\left(n g g^{-1}\right)\end{array}$ & AAE & $\begin{array}{r}\text { SP2: } \\
\text { grav.ratio }\end{array}$ & $\begin{array}{r}\text { ISSW: } \\
\text { grav.ratio }\end{array}$ \\
\hline B1 & 1192 & 0 & & 1889 & 1.3 & & 1.59 \\
\hline B2 & 1192 & 0 & 1110 & 1797 & 1.2 & 1.07 & 1.51 \\
\hline B3 & 335 & 0 & 356 & 467 & 1.5 & 0.94 & 1.39 \\
\hline B4 & 746 & 0 & 835 & 1165 & 1.3 & 0.89 & 1.56 \\
\hline B5 & 1068 & 0 & 1004 & 1268 & 1.2 & 0.94 & 1.19 \\
\hline B6 & 496 & 0 & 462 & 569 & 1.4 & 0.93 & 1.15 \\
\hline B7 & 217 & 0 & 214 & 244 & 1.5 & 0.99 & 1.12 \\
\hline B8 & 62.3 & 0 & 54 & 73 & 1.5 & 0.86 & 1.18 \\
\hline B9 & 12.2 & 0 & 16 & 9 & 1.7 & 1.27 & 0.76 \\
\hline D1 & 60.6 & 1.6 & 59 & 73 & 2.1 & 0.97 & 1.21 \\
\hline D2 & 66.5 & 5.3 & 68 & 114 & 2.5 & 1.02 & 1.71 \\
\hline D3 & 57.5 & 49.2 & 84 & 168 & 3.8 & 1.46 & 2.92 \\
\hline D4 & 454 & 2.5 & 426 & 648 & 1.5 & 0.94 & 1.43 \\
\hline D5 & 478 & 7.4 & 440 & 832 & 1.7 & 0.92 & 1.74 \\
\hline D6 & 436 & 52.1 & 440 & 1232 & 2.5 & 1.01 & 2.83 \\
\hline D7 & 0 & 8.2 & 3 & 3 & 4.3 & $\mathrm{n} / \mathrm{a}$ & $\mathrm{n} / \mathrm{a}$ \\
\hline D8 & 0 & 54.1 & 14 & -32 & 4.5 & $\mathrm{n} / \mathrm{a}$ & $\mathrm{n} / \mathrm{a}$ \\
\hline
\end{tabular}

ensure that $\leq 20 \%$ statistical uncertainty was associated with this effect in our measurements, although this was generally clearly insufficient to generate a reasonable BC size distribution.

In practice, we recommend the following steps to determine BC concentration/size distribution in single snow samples:

1. Characterize the nebulizer over a range of PSL sizes extending at least to $1.5 \mu \mathrm{m}$. If nebulization efficiency drops off sharply above $500 \mathrm{~nm}$, as in the U5000AT, we would tend to be suspicious of the size distribution/concentrations measured in unknown samples.

2. Establish stable flow in both the nebulizer and the SP2. Without stable flow, it is difficult to relate measurements separated in time (e.g., calibration of absolute nebulization efficiency and measurement of BC-containing samples). We recommend only recording particle data after concentration transients associated with changing samples have passed. In our lab, transients typically lasted less than $1 \mathrm{~m}$.

3. Sample a PSL concentration standard to establish an absolute baseline for the nebulization efficiency. We used a $505 \mathrm{~nm}$ sample based on the quality of the monodisperse distribution. We reduced laser power to allow these large particles to be sized without saturating the SP2 scatter detector.

4. Sample clean water to establish a background BC concentration due to contaminants.
5. Sample the $\mathrm{BC}$ containing sample. If $\mathrm{BC}$ concentrations do not rise above those established in the previous step, the background BC level must be reduced. This may be accomplished, for example, by using new pump tubing, by purging the nebulizer, and/or by reducing stray $\mathrm{BC}$ in the SP2 by sampling filtered air. For BC size distribution, an extended measurement to get as many $\mathrm{BC}$ particles as possible is recommended. Ideally, at least 10000 BC-containing particles are needed.

6. Resample the PSL concentration standard to establish the stability of nebulization. We observed excellent concentration stability better than $5 \%$ generally in the PSL sample nebulization efficiency measurements.

7. The $\mathrm{BC}$ mass concentration can then be calculated from the average $\mathrm{BC}$ mass $\left(M_{\mathrm{BCav}}\right)$ and PSL number $\left(C_{\mathrm{a}}\right)$ observed in each $\mathrm{cm}^{3}$ of air, via Eq. (5):

$\mathrm{BC}$ Concentration $=M_{\mathrm{BCav}} / E$

where $E$ is the absolute efficiency determined from Eq. (2) with $C_{\mathrm{a}}$ and the in-liquid PSL concentration of the standard.

8. Finally, apply the correction for the non-uniform nebulization efficiency appropriate for the size distribution of BC observed in the sample, or for a group of samples. If there was negligible contribution of $\mathrm{BC}$ in the size range of reduced relative nebulization efficiency to the total BC mass (as in the gravimetric standard shown in Fig. 2), applying the size correction was unnecessary. 


\subsection{Experimental technique for the ISSW}

The ISSW was described in detail by Grenfell et al. (2011), with additional uncertainty analysis in Doherty et al. (2010). Briefly, the ISSW spectrally resolves light absorption by snow contaminants collected on a filter for wavelengths 420 $730 \mathrm{~nm}$. Absorption associated with $\mathrm{BC}$ and non-BC material is differentiated by assuming absorption by $\mathrm{BC}$ scales with wavelength as $\lambda^{-1}$ and absorption by the non-BC constituents scales as $\lambda^{-\alpha}$, where 1.0 and $\alpha$ are the absorption Ångström exponents (AAEs) of the BC and non-BC constituents, respectively. The value of $\alpha$ used is selected based on chemical analysis of the snow melt water; if the chemical signature of combustion aerosol is dominant, $\alpha=5$ is used (Doherty et al., 2010). If high iron content is present, the snow is assumed to have dominant non-BC absorption contributions from mineral dust, and thus is analyzed with a value of $\alpha$ of 3.5. If further chemical data are available, assumptions about iron and organic carbon spectrally resolved mass absorption efficiencies can be used to estimate $\alpha$.

The fraction of absorption attributed to $\mathrm{BC}$ is converted to a mass concentration of $\mathrm{BC}$ using a set of gravimetrically determined synthetic $\mathrm{BC}$ standards that have a mass absorption coefficient (MAC) of $6.3 \mathrm{~m}^{2} \mathrm{~g}^{-1}$. If the MAC of the unknown $\mathrm{BC}$ on the filter is higher (lower) than this value, then the estimated BC mass values will be too high (low). A correction for filter undercatch of $15 \%$ is applied to field samples (Doherty et al., 2010).

The total uncertainty associated with the ISSW BC concentration determination for ambient snow has previously been estimated as $40 \%$, which is the sum, in quadrature, of $11 \%$ for instrumental uncertainty, $15 \%$ for undercatch uncertainty, $17 \%$ for BC MAC uncertainty, and $30 \%$ for uncertainty in the AAE of non-BC material (Doherty et al., 2010; Grenfell et al., 2011).

\subsection{Laboratory standards}

Gravimetric standards of $\mathrm{BC}$ (using the fullerene soot used to calibrate the SP2) and test dust (ISO-12103-1, A2 Fine Test Dust, Powder Technology, Inc., Burnsville, MN, USA), in addition to PSL concentration standards, were used to test the SP2 and ISSW. The test dust was light brown, with major components (in order of weight fraction): $\mathrm{SI}_{2}, \mathrm{Al}_{2} \mathrm{O}_{3}$, $\mathrm{Fe}_{2} \mathrm{O}_{3}, \mathrm{Na}_{2} \mathrm{O}, \mathrm{CaO}, \mathrm{MgO}, \mathrm{TiO}_{2}, \mathrm{~K}_{2} \mathrm{O}$. Mixtures of dust or $\mathrm{BC}$ in deionized water were allowed to settle for several days to remove large particles, and then the top liquid was slowly drawn off for use and drying/weighing. For the dust standards, some settled material was included in the drawn-off mixture. Note that allowing large BC particles to settle out of solution resulted in a $\mathrm{BC}$ size distribution for the standards that was narrower and smaller than that observed in snow (Fig. 2). Thus the laboratory samples do not inform us about uncertainties in the correction calculated for the SP2 due to the size dependence of the nebulizer efficiency, or the validity of the BC mass calibration extrapolation (described in Sect. 2.1).

For the $\mathrm{BC}$ standard three samples were dried to determine the $\mathrm{BC}$ concentration by weighing the solid residues, with a standard error of $6 \%$. Impurities in the dilution water contributed less than $1 \%$ to the dry weights. Master solutions of the three materials (BC, PSLs and dust) were diluted and mixed to create a wide variety of mixtures and concentrations of either pure $\mathrm{BC}$, a mixture of $\mathrm{BC}+\mathrm{PSL}$ or $\mathrm{BC}+$ dust, and $\mathrm{BC}$-free dilutions of pure PSLs or pure dust. The concentrations of dust tested roughly spanned the range observed in ambient snow samples from north and northeast China. The range of PSL concentrations was similar to that of the dust standards. The range of $\mathrm{BC}$ concentration spanned that seen in ambient snow.

The laboratory samples were prepared, placed in glass bottles, immediately characterized with the SP2 in Colorado, and then transported to the ISSW at the University of Washington for filtration within $24 \mathrm{~h}$. These samples were not frozen. Some duplicate samples were kept at room temperature to simulate changes occurring in the mailed samples. After $24 \mathrm{~h}$ they were tested with the SP2 and were found to match the fresh samples well within expected uncertainties.

For the laboratory samples, ISSW filter undercatch was much more significant than for ambient field samples, likely because of the difference in size between the fullerene soot gravimetric standards and ambient snow BC. Undercatch was $38 \pm 3 \%$ based on refiltering post-filter liquid using finer-mesh $(0.2 \mu \mathrm{m})$ nuclepore filters, and analyzing with the ISSW. We assume that the $0.2 \mu \mathrm{m}$ filters collect all the particles missed by the $0.4 \mu \mathrm{m}$ filters, because limited tests with $0.1 \mu \mathrm{m}$ filters show no difference to the $0.2 \mu \mathrm{m}$ filters. The ISSW laboratory results are scaled to remove this artifact. The fact that this correction is quite different from that applied to field samples suggests that the ISSW undercatch correction may be sensitive to the particulate size distribution in snow.

To explore the possible magnitude of a low bias in the SP2 $\mathrm{BC}$ mass determination due to $\mathrm{BC}$ internal mixing with large amounts of non-BC material (which would affect nebulization efficiency), two analyses were performed. First, a test using laboratory samples bounded the number-fraction of $\mathrm{BC}$ particles in solution that became attached to dust particles during a single freeze/thaw cycle; only $\sim 1 \%$ did. Second, the number fraction of $\mathrm{BC}$ particles associated with detectable (by the SP2) amounts of non-BC material was calculated for field samples (as in Schwarz et al., 2008). On the whole, the fraction showed that the $\mathrm{BC}$ was predominantly bare, within variability from sample to sample, and that the acidification process did not result in any measurable additional coatings on the $\mathrm{BC}$. These results indicate that this mechanism is unlikely to broadly bias the SP2 results shown here. 


\section{Laboratory results}

Figure 3 shows the results of measurements of $\mathrm{BC}$ and non$\mathrm{BC}$ concentration standards. For pure $\mathrm{BC}$-in-water samples, the SP2 and ISSW produced values that correlated strongly with each other with very little scatter. This correlation revealed common mode variations in the gravimetric value at the level of $\sim 10 \%$ from the mean that we attribute to inaccuracies in diluting the samples. These variations do not affect our conclusions. The SP2 values matched, within uncertainties, the gravimetrically determined concentration of BC. The ISSW values were biased high by a factor $1.40 \pm 9 \%$, likely due to differences in the optical properties of the fullerene material used in the gravimetric standards and the ISSW calibration material (Monarch 71). Note that this $40 \%$, which may include scattering effects aas well as any shift in MAC value, exceeds the previous ISSW estimate of MAC uncertainty, which was closer to $20 \%$. A mass absorption coefficient of $8.84 \mathrm{~m}^{2} \mathrm{~g}^{-1}$ for the fullerene soot, which is well within range associated with $\mathrm{BC}$, would correspond to this $40 \%$. Use of an incorrect assumed value of the AAE for $\mathrm{BC}$ (in this case the fullerene) will also produce a bias in the ISSW BC estimates. The pure fullerene samples have an ISSW-measured AAE of $1.2 \pm 0.2$, not the assumed 1.0. Accounting for this, however, increased the bias by an additional $\sim 15 \%$.

The SP2 proved to have a small positive offset associated with dust content, and none with PSLs. The SP2 sensitivity to dust was caused by incandescent signals associated with small amounts of dust that produced visible light signals through heating in the laser. In real snow samples with low $\mathrm{BC}$ concentrations, it would be difficult to separate these signals from those of $\mathrm{BC}$. The $\mathrm{BC}$-equivalent sizes of these signals were predominantly below $500 \mathrm{~nm}$ VED. In the most dust-contaminated samples (containing $\sim 50 \mu \mathrm{g}-$ dust $/ \mathrm{g}-\mathrm{H}_{2} \mathrm{O}$ ), this led to a $15 \mathrm{ng}-\mathrm{BC} / \mathrm{g}-\mathrm{H}_{2} \mathrm{O}$ positive offset in the SP2 BC determination. Note that real BC content in the dust sample contributes to this conservative estimate of sensitivity, and that dust composition independent of BC content could also affect it. It is possible that this effect could be reduced via stringent discrimination of particle microphysical properties (including color temperature and scattering cross-section normalized to incandescent light signal) coupled with additional validation on well-controlled laboratory samples. For example, we examined the colortemperature values associated with the large $\mathrm{BC}$ particles in snow, and found that they were consistent with BC composition. Hence we are confident that dust does not significantly affect the observed BC size distributions. The relative impact of this dust sensitivity depends on the absolute amount of BC present in snow. In the Arctic, BC loadings of only $25 \mathrm{ng} \mathrm{g}^{-1}$ are common (Doherty et al., 2010), although the absolute amount of dust present is expected to be less than the amount in the most-dust contaminated snow. The ISSW results revealed positive biases associated with contamination

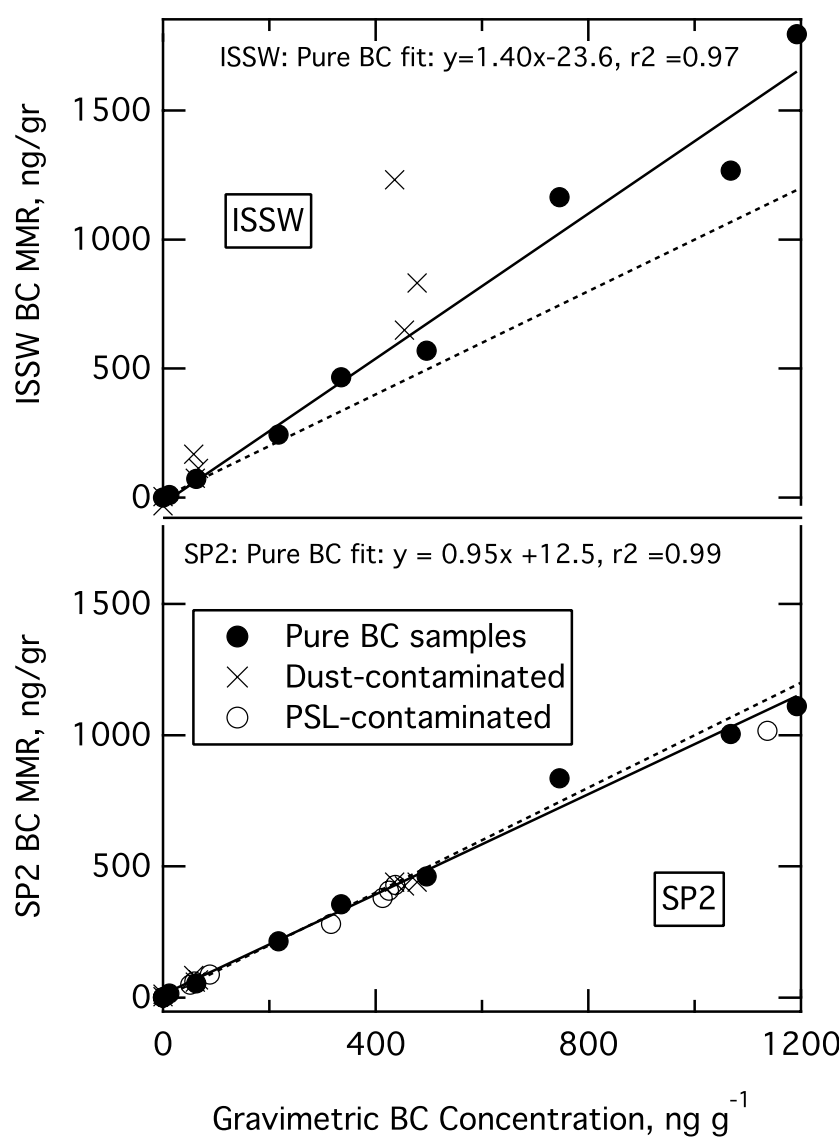

Fig. 3. Top: ISSW determinations of laboratory mixtures of fullerene soot and test dust with water; increasing concentrations of dust lead to increasing deviation from the pure-BC trend. Bottom: SP2 determinations for these samples, and additionally for samples contaminated with PSLs. The solid lines represent best-fit lines only to uncontaminated BC-in-water samples. Dashed lines are 1-to-1.

of the BC samples with both PSLs and with dust. For Fig. 3, the ISSW values were calculated using an $\alpha$ (non-BC AAE) of 4.4, based on unambiguous ISSW measurements of pure dust-in-water samples at several concentrations, and hence represent a "best-case" evaluation; use of this $\alpha$ results in a lack of dependence of the relative bias on the amount of $\mathrm{BC}$ present. The high bias was as high as a factor 3 for the most dust-contaminated samples. Non-BC AAE was varied from 3.5-5.0 to test for the ISSW sensitivity to this parameter. The former is based on measurements of ambient dust AAE, which range from approximately 2 to 4 (e.g., Fialho et al., 2006; Alfaro et al., 2004; Bergstrom et al., 2007; Yang et al., 2009). The latter is an appropriate $\alpha$ for combustion aerosol (Doherty et al., 2010). For $\alpha=3.5$, lower than the appropriate 4.4, the relative bias between estimated BC concentration and gravimetric $\mathrm{BC}$ became strongly dependent on the $\mathrm{BC}$ concentration in the sample, with non-physical negative $\mathrm{BC}$ concentration estimates at high dust-to-BC ratios (Tables 1 and 2). With assumed $\alpha=5.0$, larger than the 
Table 2. The ratio of ISSW measured concentration to the gravimetric concentration ("grav") calculated for different values of $\alpha$ for the dust-containing samples.

\begin{tabular}{lrrrrr}
\hline $\begin{array}{l}\text { Sample } \\
\text { label }\end{array}$ & $\begin{array}{r}\text { GC concentration } \\
\left(\mathrm{ng} \mathrm{g}^{-1}\right)\end{array}$ & $\begin{array}{r}\text { Ratio dust: BC } \\
\left(10^{3}\right)\end{array}$ & $\begin{array}{r}\text { ISSW: grav. } \\
\alpha=3.5\end{array}$ & $\begin{array}{r}\text { ISSW: grav. } \\
\alpha=4.4\end{array}$ & $\begin{array}{r}\text { ISSW: grav. } \\
\alpha=5\end{array}$ \\
\hline D1 & 60.6 & 0.03 & 1.01 & 1.21 & 1.30 \\
D2 & 66.5 & 0.08 & 1.21 & 1.71 & 1.92 \\
D3 & 57.5 & 0.86 & -2.43 & 2.92 & 5.16 \\
D4 & 454 & 0.01 & 1.34 & 1.43 & 1.46 \\
D5 & 478 & 0.02 & 1.58 & 1.74 & 1.81 \\
D6 & 436 & 0.12 & 2.02 & 2.83 & 3.16 \\
\hline
\end{tabular}

appropriate 4.4 , a purely positive bias with a stronger dependence on dust-to-BC ratio was observed. These high biases are larger than expected based on the uncertainty analysis from Doherty et al. (2010). For pure BC standards this range of $\alpha$ resulted in only a $5 \%$ range in estimated $\mathrm{BC}$ concentration.

The monodisperse nature of the PSL-containing test standards produced strong wavelength dependencies in the inferred ISSW absorption, at wavelengths used to separate BC and non-BC absorbance contributions. As this type of behavior is not seen in ambient samples, these results are not quantitatively presented in the context of absolute ISSW uncertainty. However, as the PSL scattering artifacts caused an "absorption" signal in the ISSW that was roughly equivalent to a factor 2-5 overestimate in $\mathrm{BC}$ loading for a range of PSL-to-BC mass mixing ratio of 10-450, this indicates that the ISSW does have a positive artifact associated with non-absorbing particulate matter. The size of the excursions suggests that purely scattering particles could significantly bias ISSW absorption measurements. This sensitivity to light scattering may contribute to the two separate biases that appear to be affecting the ISSW results: the bias of $\sim 40 \%$ in the pure BC (fullerene soot) samples that may be due to the MAC of the gravimetric standard material and/or the scattering properties of the standard relative to the usual ISSW absorption standard; and a high relative bias that is a function of non-BC aerosol concentration. The use of the optimal values of $\alpha$ for these laboratory samples indicates that even detailed information about the absorption spectra of non-BC impurities is insufficient to remove the ISSW sensitivity to the presence of other aerosol constituents.

An additional issue also indicates sensitivity of the ISSW to non-BC in snow. The ISSW results depend on whether snow melt from dust-heavy samples is stirred just previous to sampling. Presumably, this incorporates larger dust particles into the liquid that would otherwise settle out; in fact stirred samples have shown substantially higher BC loads in the ISSW than "settled" snow samples. However, the SP2 results revealed neither significant dependence on stirring/shaking samples before sampling, nor any drifts in BC concentration in snow over timescales of $1 \mathrm{~h}$ during non-agitated sampling.

\section{Conclusions}

We find that BC in snow can be present at larger sizes than in the typical ambient atmosphere. This has implications for determinations of $\mathrm{BC}$ mass content in snow, as well as possible implications for our understanding of the roles of $\mathrm{BC}$ in affecting snow albedo and in evincing snow history. Due in part to the potential for large sizes of BC in snow, use of the SP2 for BC-in-liquid measurements requires careful characterization of nebulization efficiency as a function of particle size, as well as, potentially, extrapolation of instrument response to very large $\mathrm{BC}$ masses. The inherent uncertainties associated with these complications are unlikely to be amenable to substantial reduction, yet are still small enough that the SP2 technique can contribute meaningful information about $\mathrm{BC}$ content in liquid. We estimate that the SP2 can provide a measurement of $\mathrm{BC}$ in snow with $60 \%$ systematic uncertainty, dominated by calibration uncertainty and limiting assumptions about the size distribution of BC in the snowmelt. A necessary assumption is that $\mathrm{BC}$ mass attached to larger particulate materials $(\gtrsim 2 \mu \mathrm{m})$ in the snow mass, or in sizes smaller than the accumulation mode is negligible. This assumption is supported by the observed BC mass size distributions shown in the paper, and by tests indicating that $\mathrm{BC}$ does not tend to be associated with large amounts of non$\mathrm{BC}$ material in individual particles. The SP2 can provide the size distribution of $\mathrm{BC}$ in snow, within the range of sizes aerosolized with reasonable efficiency, and within the calibration range applicable to the SP2. Due to these issues, previous SP2 determinations of BC concentration in snow or ice formed from fallen snow may be associated with uncertainties significantly larger than estimated. We recommend careful assessment of the size dependence of the nebulization efficiency when using the SP2 to study the size distribution or mass concentration of $\mathrm{BC}$ in liquids.

The SP2 has a small positive artifact due to the difficulty of separating mass contributions of the uncommon nonBC materials that incandesce like BC. Based on laboratory tests with dust, this artifact is conservatively estimated to be $\mathrm{a}+15 \mathrm{ng} \mathrm{g}^{-1}$ offset in the most highly contaminated samples, equivalent to the most dust-laden snow samples from a 
recent field sampling campaign in central China (Huang et al., 2011). Previous determinations of BC in samples with dust contamination with the SP2 may be sensitive to this effect.

Laboratory testing of the ISSW revealed biases associated with both non-BC light-absorbing and purely scattering particulate in water. For dust, this bias was proportional to the amount of contaminant, with a value $\sim \pm 25 \%$ at low dust concentration and, at the highest dust concentrations, peaking at a factor 3 and offsetting $\mathrm{BC}$ concentration values by up to $\sim 600 \mathrm{ng}-\mathrm{BC} / \mathrm{g}-\mathrm{H}_{2} \mathrm{O}$. This bias is inconsistent with the current uncertainty estimate for the ISSW. The fact that the ISSW responded to non-absorbing impurities indicates that the single-scatter albedo (SSA) of the aerosol can change ISSW BC concentration determinations. This suggests that the size distribution and mixing state of material on the filter may impact ISSW results. Additionally, we are not able to distinguish the contribution of this scattering artifact to the biases associated with dust mixed into $\mathrm{BC}$ gravimetric standards; the observed high bias in ISSW-derived BC in the presence of dust impurities may be due entirely to scattering sensitivity.

These results support recent concern about the relative contribution of BC to total absorption in snow. Results with the ISSW in the Arctic (Doherty et al., 2010), which themselves suggested that non-BC absorbers play a significant role in snowpack light absorption by particulates, may need to be revised further to a point where $\mathrm{BC}$ is not the primary absorbing material in the snow.

Acknowledgements. We thank Tony Clarke, University of Hawaii, for helpful discussion and commentary; Greg Kok, Droplet Measurement Technology, Inc., for use of the U5000AT nebulizer; Brad Pierce, NOAA ESRL/GMD, for use of high precision weighing equipment; and Erena Schwarz, Boulder, CO, for collection of local snow samples.

Edited by: A. Kokhanovsky

\section{References}

Adachi, K., S., Chung, H., and Buseck, P. R.: Shapes of soot aerosol particles and implications for their effects on climate, J. Geophys. Res., 115, D15206, doi:10.1029/2009JD012868, 2010.

Alfaro, S. C., Lafon, S., Rajot, L., Formenti, P., Gaudichet, A., and Maille, M.: Iron oxides and light absorption by pure desert dust: an experimental study, J. Geophys. Res., 109, D08208, doi:10.1029/2003JD004374, 2004.

Baumgardner, D., Popovicheva, O., Allan, J., Bernardoni, V., Cao, J., Cavalli, F., Cozic, J., Diapouli, E., Eleftheriadis, K., Genberg, P. J., Gonzalez, C., Gysel, M., John, A., Kirchstetter, T. W., Kuhlbusch, T. A. J., Laborde, M., Lack, D., Müller, T., Niessner, R., Petzold, A., Piazzalunga, A., Putaud, J. P., Schwarz, J., Sheridan, P., Subramanian, R., Swietlicki, E., Valli, G., Vecchi, R., and Viana, M.: Soot reference materials for instrument calibration and intercomparisons: a workshop summary with recommendations, Atmos. Meas. Tech., 5, 1869-1887, doi:10.5194/amt-51869-2012, 2012.

Bergstrom, R. W., Pilewskie, P., Russell, P. B., Redemann, J., Bond, T. C., Quinn, P. K., and Sierau, B.: Spectral absorption properties of atmospheric aerosols, Atmos. Chem. Phys., 7, 5937-5943, doi:10.5194/acp-7-5937-2007, 2007.

Bisiaux, M. M., Edwards, R., McConnell, J. R., Albert, M. R., Anschütz, H., Neumann, T. A., Isaksson, E., and Penner, J. E.: Variability of black carbon deposition to the East Antarctic Plateau, 1800-2000 AD, Atmos. Chem. Phys., 12, 3799-3808, doi:10.5194/acp-12-3799-2012, 2012a.

Bisiaux, M. M., Edwards, R., McConnell, J. R., Curran, M. A. J., Van Ommen, T. D., Smith, A. M., Neumann, T. A., Pasteris, D. R., Penner, J. E., and Taylor, K.: Changes in black carbon deposition to Antarctica from two high-resolution ice core records, 1850-2000 AD, Atmos. Chem. Phys., 12, 4107-4115, doi:10.5194/acp-12-4107-2012, 2012 b.

Clarke, A. D., Noone, K. J., Heintzenberg, J., Warren, S. G., and Covert, D. S.: Aerosol light absorption measurement techniques: analysis and intercomparisons, Atmos. Environ., 21, 1455-1465, 1987.

Cross, E. S., Onasch, T. B., Ahern, A., Wrobel, W., Slowik, J. G., Olfert, J., Lack, D. A., Massoli, P., Cappa, C. D., Schwarz, J. P., Spackman, J. R., Fahey, D. W., Sedlacek, A., Trimborn, A., Jayne, J. T., Freedman, A., Williams, L. R., Ng, N. L., Mazzoleni, C., Dubey, M., Brem, B., Kok, G., Freitag, S. R., Clarke, A., Thornhill, D., Marr, L. C., Kolb, C. E., Worsnop, D. R., and Davidovits, P.: Soot Particle Studies Instrument Inter-Comparison Project Overview, Aerosol Sci. Technol., 44, 175-181, 2010.

Doherty, S. J., Warren, S. G., Grenfell, T. C., Clarke, A. D., and Brandt, R. E.: Light-absorbing impurities in Arctic snow, Atmos. Chem. Phys., 10, 11647-11680, doi:10.5194/acp-1011647-2010, 2010.

Fialho, P., Freitas, M. C., Barata, F., Vieira, B., Hansen, A. D. A., and Honrath, R. E.: The Aethalometer calibration and determination of iron concentration in dust aerosols, J. Aerosol Sci., 37, 1497-1506, 2006.

Flanner, M. G., Zender, C. S., Randerson, J. T., and Rasch, P. J.: Present-day climate forcing and response from black carbon in snow, J. Geophys. Res., 112, D11202, doi:10.1029/2006JD008003, 2007.

Grenfell, T. C., Doherty, S. J., Clarke, A. D., and Warren, S. G.: Light absorption from particulate impurities in snow and ice determined by spectrophotometric analysis of filters, Appl. Opt., 50, 2037-2048, 2011.

Gysel, M., Laborde, M., Olfert, J. S., Subramanian, R., and Gröhn, A. J.: Effective density of Aquadag and fullerene soot black carbon reference materials used for SP2 calibration, Atmos. Meas. Tech., 4, 2851-2858, doi:10.5194/amt-4-2851-2011, 2011.

Hinds, W. C.: Aerosol Technology, Wiley-interscience, 1999.

Huang, J., Fu, Q., Zhang, W., Wang, X., Zhang, R., Ye, H., and Warren, S. G.: Dust and black carbon in seasonal snow across northern China, B. Am. Meteorol. Soc., 92, 175-181, doi:10.1175/2010BAMS3064.1, 2011.

Kaspari, S. D., Schwikowsk, M., Gysel, M., Flanner, M. G., Kang, S., Hou, S., and Mayewski, P. A.: Recent increase in black carbon concentrations from a Mt. Everest ice core spanning 1860-2000 AD, Geophys. Res. Lett., 38, L04703, 
doi:10.1029/2010GL046096, 2011.

Li, F., Schafer, R., Hwang, C. T., Tanner, C. E., and Ruggiero, S. T.: High-precision sizing of nanoparticles by laser transmission spectroscopy, Appl. Opt., 49, 6602-6611, 2010.

McConnell, J. R., Edwards, R., Kok, G. L., Flanner, M. G., Zender, C. S., Saltzman, E. S., Banta, J. R., Pasteris, D. R., Carter, M. M., and Kahl, J. D. W.: 20th-century industrial black carbon emissions altered Arctic climate forcing, Science, 317, 5843, 1381-1384, 2007.

Moteki, N. and Kondo, Y.: Dependence of laser-induced incandescence on physical properties of black carbon aerosols: Measurements and theoretical interpretation, Aerosol Sci. Tech., 44, 663$675,2010$.

Ohata, S., Moteki, N., and Kondo, Y.: Evaluation of a method for measurement of the concentration and size distribution of black carbon particles suspended in rainwater, Aerosol Sci. Technol., 45, 1326-1336, 2011.

Olfert, J. S. and Collings, N.: New method for particle mass classification - the Couette centrifugal particle mass analyzer, J. Aerosol Sci., 36, 1338-1352, 2005.

Schwarz, J. P., Gao, R. S, Fahey, D. W., Thomson, D. S., Watts, L. A., Wilson, J. C., Reeves, J. M.,Darbeheshti, M., Baumgardner, D. G., Kok, G. L., Chung, S. H., Schulz, M., Hendricks, J., Lauer, A, Kärcher, B., Slowik, J. G., Rosenlof, K. H., Thompson, T. L., Langford, A. O., Loewenstein, M., and Aikin, K. C.: Single-Particle measurements of midlatitude black carbon and light-scattering aerosols from the boundary layer to the lower stratosphere, J. Geophys. Res., 110, D16207, doi:10.1029/2006JD007076, 2006.
Schwarz, J. P., Spackman, J. R., Fahey, D. W., Gao, R. S., Lohmann, U., Stier, P., Watts, L. A., Thomson, D. S., Lack, D. A., Pfister, L., Mahoney, M. J., Baumgardner, D., Wilson, J. C., and Reeves, J. M.: Coatings and their enhancement of black carbon light absorption in the tropical atmosphere, J. Geophys. Res., 113, D03203, doi:10.1029/2007JD009042, 2008.

Schwarz, J. P., Spackman, J. R., Gao, R. S., Perring, A. E., Cross, E., Onasch, T. B., Ahern, A., Wrobel, W., Davidovits, P., Olfert, J., Dubey, M. K., Mazzoleni, C., and Fahey, D. W.: The detection efficiency of the single particle soot photometer, Aerosol Sci. Tech., 44, 612-628, doi:10.1080/02786826.2010.481298, 2010a.

Schwarz, J. P., Spackman, J. R., Gao, R. S., Watts, L. A., Stier, P., Schulz, M., Davis, S. M., Wofsy, S. C., and Fahey, D. W.: Global-scale black carbon profiles observed in the remote atmosphere and compared to models, Geophys. Res. Lett., 37, L18812, doi:10.1029/2010GL044372, 2010 b.

Yang, M., Howell, S. G., Zhuang, J., and Huebert, B. J.: Attribution of aerosol light absorption to black carbon, brown carbon, and dust in China - interpretations of atmospheric measurements during EAST-AIRE, Atmos. Chem. Phys., 9, 2035-2050, doi:10.5194/acp-9-2035-2009, 2009. 